\title{
Amperometric Sensor Based on Carbon Nanotubes and Polycations for the Determination of Vitamin C
}

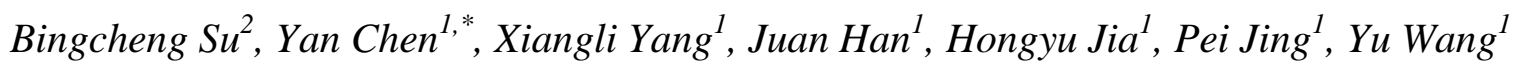 \\ ${ }^{1}$ College of Environmental Science and Engineering, Shandong Agriculture and Engineering \\ University, Jinan, 250100, P. R. China \\ 2 Jinan Licheng No. 2 High School, Jinan, 250000, P. R. China \\ *E-mail: ychen0612@163.com
}

doi: $10.20964 / 2017.07 .26$

Received: 4 March 2017 / Accepted: 25 April 2017 / Published: 12 June 2017

\begin{abstract}
Detection of vitamin C (VC) is necessary because of its wide use in chemical, biological, and pharmaceutical engineering. Here, we describe a sensing system for the determination of VC. Instead of a bare glassy carbon electrode (GCE), a prepared multi-walled carbon nanotube-polycation-GCE was used to detect $\mathrm{VC}$ in samples with higher sensitivity, better repeatability, and with a lower detection limit. Under the optimal conditions, the obtained sensor presented a linear response to VC in the range of $1-100 \mu \mathrm{M}$ with a detection limit of $500 \mathrm{nM}$. The proposed electrode also successfully detected VC concentrations in real samples.
\end{abstract}

Keywords: Electrochemical detection; vitamin C; polycation; nanocomposite; protamine

\section{$\underline{\text { FULL TEXT }}$}

(C) 2017 The Authors. Published by ESG (www.electrochemsci.org). This article is an open access article distributed under the terms and conditions of the Creative Commons Attribution license (http://creativecommons.org/licenses/by/4.0/). 